\title{
Molecularly targeted therapy for the treatment of head and neck cancer: a review of the ErbB family inhibitors
}

This article was published in the following Dove Press journal:

OncoTargets and Therapy

4 April 2016

Number of times this article has been viewed

\author{
Assuntina G Sacco' \\ Francis PWorden ${ }^{2}$ \\ 'Department of Internal Medicine, \\ Division of Hematology/Oncology, \\ University of California at San Diego \\ Moores Cancer Center, La Jolla, \\ CA, USA; ${ }^{2}$ Department of Internal \\ Medicine, Division of Hematology/ \\ Oncology, University of Michigan \\ Health System, Ann Arbor, MI, USA
}

Correspondence: Francis P Worden Department of Internal Medicine, Division of Hematology/Oncology, University of Michigan Health System, C369 Med Inn Building, SPC 5848, I500 E. Medical Center Drive, Ann Arbor, MI 48109, USA

Tel +l 7349360453

Fax +I 7346152109

Email fworden@med.umich.edu
Abstract: The majority of patients with head and neck squamous cell carcinoma (HNSCC) present with locally advanced disease, which requires site-specific combinations of surgery, radiation, and chemotherapy. Despite aggressive therapy, survival outcomes remain poor, and treatment-related morbidity is not negligible. For patients with recurrent or metastatic disease, therapeutic options are further limited and prognosis is dismal. With this in mind, molecularly targeted therapy provides a promising approach to optimizing treatment efficacy while minimizing associated toxicity. The ErbB family of receptors (ie, epidermal growth factor receptor [EGFR], ErbB2/human epidermal growth factor receptor [HER]-2, ErbB3/HER3, and ErbB4/HER4) is known to contribute to oncogenic processes, such as cellular proliferation and survival. EGFR, specifically, is upregulated in more than $90 \%$ of HNSCC, has been implicated in radiation resistance, and correlates with poorer clinical outcomes. The central role of EGFR in the pathogenesis of HNSCC suggests that inhibition of this pathway represents an attractive treatment strategy. As a result, EGFR inhibition has been extensively studied, with the emergence of two classes of drug therapy: monoclonal antibodies and tyrosine kinase inhibitors. While the monoclonal antibody cetuximab is currently the only US Food and Drug Administration-approved EGFR inhibitor for the treatment of HNSCC, numerous investigational drugs are being evaluated in clinical trials. This paper will review the role of the ErbB family in the pathogenesis of HNSCC, as well as the evidence-based data for the use of ErbB family inhibition in clinical practice.

Keywords: head and neck cancer, epidermal growth factor receptor, monoclonal antibody, tyrosine kinase inhibitor

\section{Introduction}

Head and neck cancer is the seventh most common cancer worldwide. ${ }^{1}$ In the United States, head and neck squamous cell carcinoma (HNSCC) accounts for $3 \%$ of cancers diagnosed annually and $2 \%$ of cancer-related deaths. ${ }^{2}$ The 2014 estimates for the number of new cases of HNSCC and anticipated deaths from HNSCC in the United States are approximately 55,000 and 12,000, respectively. ${ }^{2}$ Tobacco and alcohol use remain the strongest risk factors for HNSCC, act synergistically, and are implicated in the majority of diagnoses. ${ }^{3,4}$ Viral etiologies have also been implicated; specifically, Epstein-Barr virus is present in a significant proportion of nasopharyngeal cancers, whereas high-risk human papillomavirus (HPV) is now the primary cause of oropharyngeal cancers (OPCs). ${ }^{5-7}$

More than half the patients with HNSCC present with potentially curable, locally advanced (LA) disease, or disease that has spread to nearby tissue or lymph nodes, but has not metastasized. ${ }^{8}$ Historically, surgery was the mainstay of treatment for HNSCC; 
however, the advent of functional organ preservation in the last few decades has shifted the treatment paradigm to include definitive chemoradiation (CRT). While early-stage disease is routinely treated with surgery or radiation (RT) alone, LA disease typically requires site-specific multimodal therapy. ${ }^{9}$ Although survival rates improved over the last few decades, $30 \%-60 \%$ of patients still develop local recurrences, and approximately $20 \%$ develop distant metastases. ${ }^{8}$ For patients with recurrent or metastatic ( $\mathrm{R} / \mathrm{M})$ HNSCC, therapeutic options remain limited, and prognosis is dismal. The most active cytotoxic regimens are platinum-based and are associated with response rates (RRs) of up to $30 \%$ and median overall survival (OS) of 6-9 months..$^{10,11}$

Unfavorable survival outcomes coupled with the toxicity of current treatments underscore the importance of incorporating targeted therapies within the treatment paradigm. Epidermal growth factor receptor (EGFR) is the most wellstudied member of the ErbB family and is overexpressed in more than $90 \%$ of HNSCC. ${ }^{12-15}$ Furthermore, there is a correlation between increased EGFR levels and higher stage disease, increased lymph node metastasis, shorter relapsefree survival, and decreased OS. ${ }^{12,14-18}$ Not surprisingly, targeting the ErbB family is an area of avid research. This paper focuses on the role of the ErbB family in the pathogenesis of HNSCC, and the clinical data evaluating ErbB family inhibition for the management of HNSCC.

\section{Methods}

To identify relevant clinical trials of ErbB family inhibitors in HNSCC, PubMed and ClinicalTrials.gov databases were searched using the key search terms or aliases "ErbB" and "HNSCC". In addition, abstracts presented at the European Cancer Congress, European Society of Medical Oncology, and American Society of Clinical Oncology meetings were evaluated.

\section{The ErbB family in HNSCC}

The ErbB family consists of four transmembrane receptors, EGFR/ErbB1/human epidermal growth factor receptor (HER)-1, ErbB2/HER2/neu, ErbB3/HER3, and ErbB4/ HER4. ${ }^{19,20}$ ErbB signaling activation begins with binding of natural ligands (typically epidermal growth factor [EGF] and transforming growth factor [TGF]- $\alpha$ ) to EGFR, ErbB3, or ErbB4. ErbB2 has no known soluble ligands, but is the preferred heterodimerization partner for EGFR. Ligand binding leads to receptor homo- or heterodimerization with other ErbB family receptors (eg, ErbB2). ${ }^{19,20}$ Upon dimerization, intracellular tyrosine residues undergo autophosphorylation, triggering a cascade of downstream effects. Four primary signaling pathways have been implicated in downstream EGFR signaling: 1) phosphatidylinositol-3-kinase (PI3K)/v-akt murine thymoma viral oncogene homologue (Akt), 2) Ras/Raf/ mitogen-activated protein kinase (MAPK), 3) phospholipase-C (PLC)- $\gamma /$ protein kinase $\mathrm{C}$ (PKC), and 4) signal transducers and activators of transcription (STAT) pathways. ${ }^{21}$ These pathways culminate in the transcription of genes involved in cellular proliferation, invasion, metastasis, cell survival, and angiogenesis (Figure 1). ${ }^{19-22}$

In HNSCC, increased ErbB expression has been linked to poor outcomes, including decreased OS, locoregional relapse, and treatment failure. ${ }^{16,23,24}$ Biomarker analysis from a prospective Phase III trial demonstrated that high EGFR expression was associated with significantly shorter OS $(P=0.0006)$ and disease-free survival (DFS; $P=0.0016)$, and higher locoregional relapse rates $(P=0.0031) .{ }^{16}$

$E r b B 2$ gene expression and ErbB3 protein expression have been linked to reduced treatment response and poor outcomes in laryngopharyngeal cancer. ${ }^{23,24}$ In a study that investigated molecular correlates of locoregional failure following CRT, overexpression of ErbB2 or MDM2 proto-oncogene, E3 ubiquitin protein ligase (MDM2) was identified as an independent predictor of decreased locoregional DFS. ${ }^{23}$ Microarray analysis of samples from primary, metastatic, and recurrent HNSCC demonstrated that ErbB3 overexpression was more common in metastases than in primary lesions $(P=0.003)$, was associated with shorter survival compared with negative ErbB3 levels (median survival, 22 vs 40 months; $P=0.027$ ), and was an independent prognostic predictor of OS (hazard ratio [HR], $1.51 ; 95 \%$ confidence interval $[\mathrm{CI}], 1.01-2.23 ; P=0.040]){ }^{24}$ In patients with oral squamous cell carcinoma (SCC), combined expression of EGFR, ErbB2, and ErbB3 was more predictive of reduced survival, with ErbB2 demonstrating the strongest correlation. ${ }^{17}$

\section{ErbB family signaling and RT sensitization}

ErbB signaling may modulate response to RT. ${ }^{25,26}$ EGFR overexpression has been linked to poor RT responses in glioblastoma multiforme ${ }^{25}$ and SCC cell lines, ${ }^{27,28}$ and ErbB2 and ErbB3 expression have been associated with gefitinib resistance in HNSCC cell lines. ${ }^{26}$

Several mechanisms may underlie the association between ErbB family members and responses to RT. ${ }^{27-29}$ In human SCC cell lines, ionizing RT stimulates kinase activity via ErbB receptors, resulting in downstream activation of intracellular proliferative pathways. ${ }^{27-29}$ In addition, 


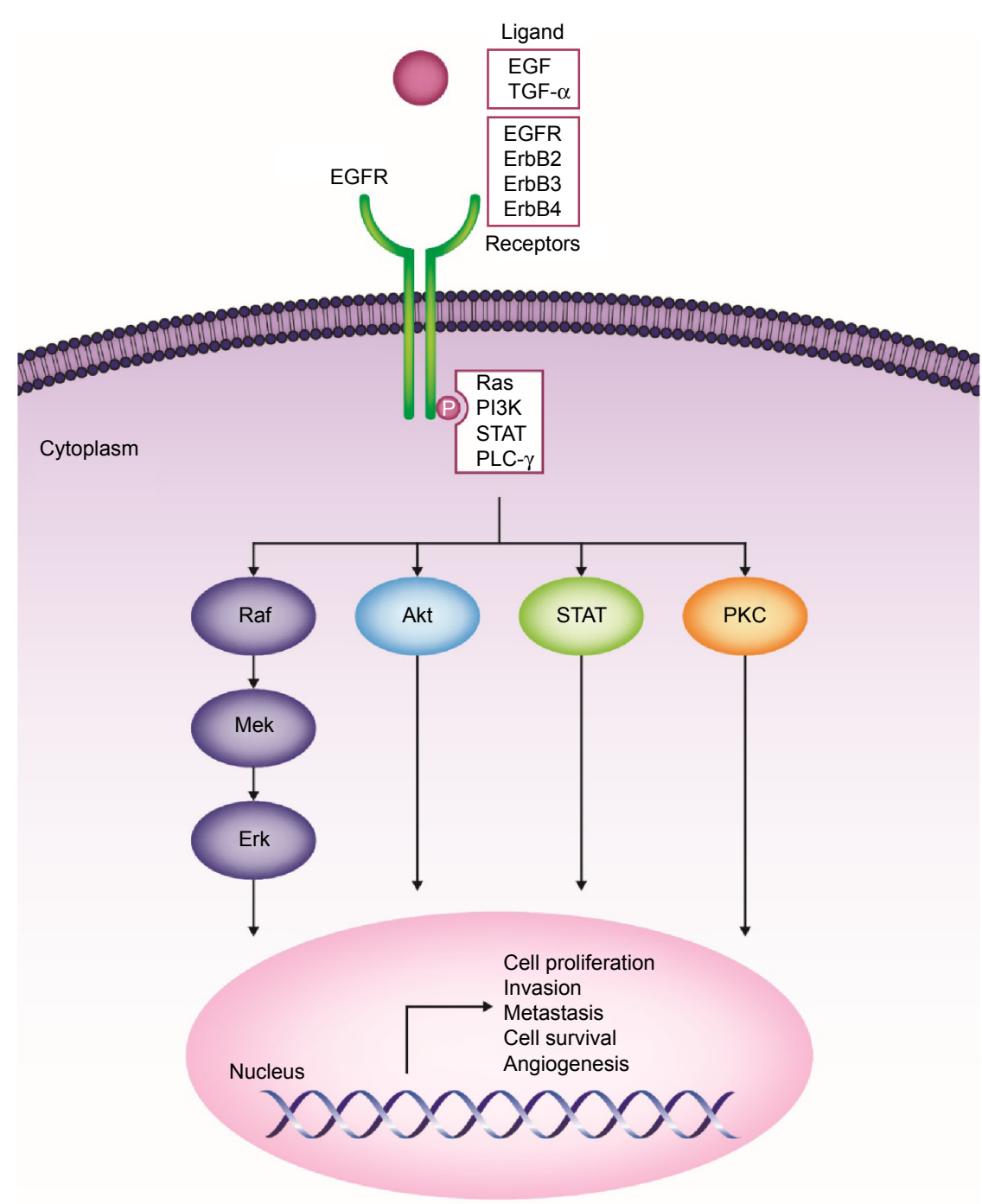

Figure I ErbB family of receptors and their associated signaling pathways and downstream effects.

Abbreviations: Akt, v-akt murine thymoma viral oncogene homologue; EGF, epidermal growth factor; EGFR, epidermal growth factor receptor; Erk, extracellular signalrelated kinase; Mek, mitogen-activated protein kinase kinase; PI3K, phosphatidylinositol-3-kinase; PLC- $\gamma$, phospholipase-C gamma; PKC, protein kinase C; Ras, rat sarcoma viral oncogene homologue; Raf, Raf proto-oncogene, serine/threonine kinase; STAT, signal transducers and activators of transcription; TGF- $\alpha$, transforming growth factor alpha.

cytoprotective pathways triggered via EGFR may increase cell survival in response to RT. ${ }^{30}$ In human SCC cell lines, ionizing RT triggers ligand-independent caveolin-driven nuclear translocation of EGFR and formation of a complex with DNA-dependent protein kinase, thereby preventing DNA repair after RT exposure. ${ }^{31}$ In addition, RT may allow tumor cells to circumvent EGF-mediated growth inhibition. RT exposure promotes entry of SCC cells into S- and $\mathrm{G}_{2} / \mathrm{M}$ phases after stimulation with EGF and ionizing RT, significantly increasing SCC proliferation in an EGFR-dependent manner; ${ }^{27}$ this suggests that EGFR may play a role in post-RT tumor repopulation. ${ }^{27,32}$ Finally, EGFR overexpression has been implicated in fostering cancer stem cell survival, including expression of certain cancer stem cell genes and tumorsphere formation in HNSCC cell lines. ${ }^{33}$

\section{Clinical data on ErbB family inhibitors in HNSCC}

There are two classes of available agents with anti-EGFR activity: monoclonal antibodies (mAbs) and tyrosine kinase inhibitors (TKIs). mAbs act at the receptor's extracellular domain, whereas TKIs act on the cytosolic adenosine triphosphate-binding domain of EGFR to inhibit autophosphorylation. ${ }^{34}$ Cetuximab is the first and only targeted therapy approved by the US Food and Drug Administration (FDA) for the treatment of HNSCC. ${ }^{35}$ This agent has the most robust clinical data among ErbB family inhibitors and is routinely used in clinical practice. Other targeted agents are currently being investigated in HNSCC. Herein, we discuss Phase II and III data available for ErbB family inhibitors, including completed (Tables 1-3) and ongoing trials (Table 4). 


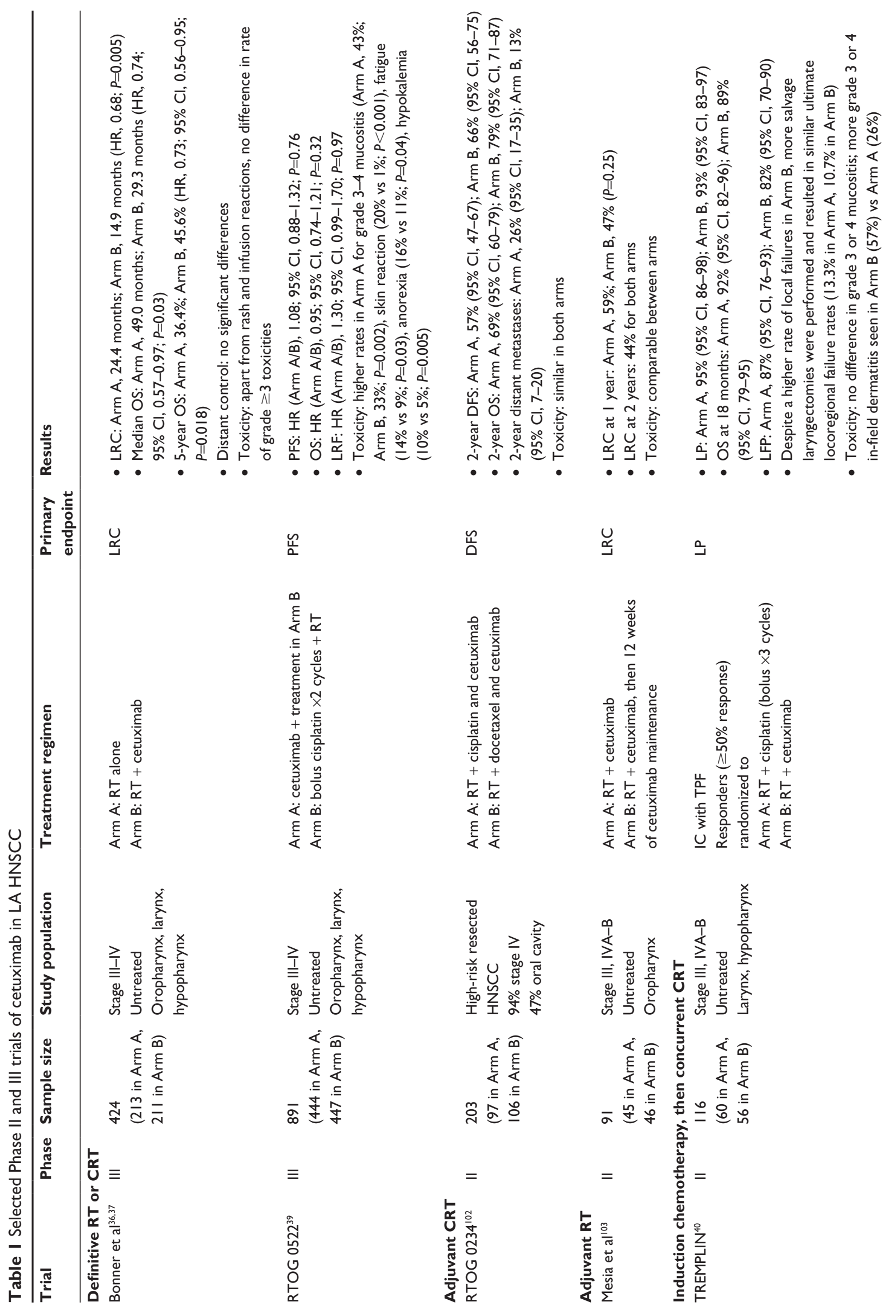




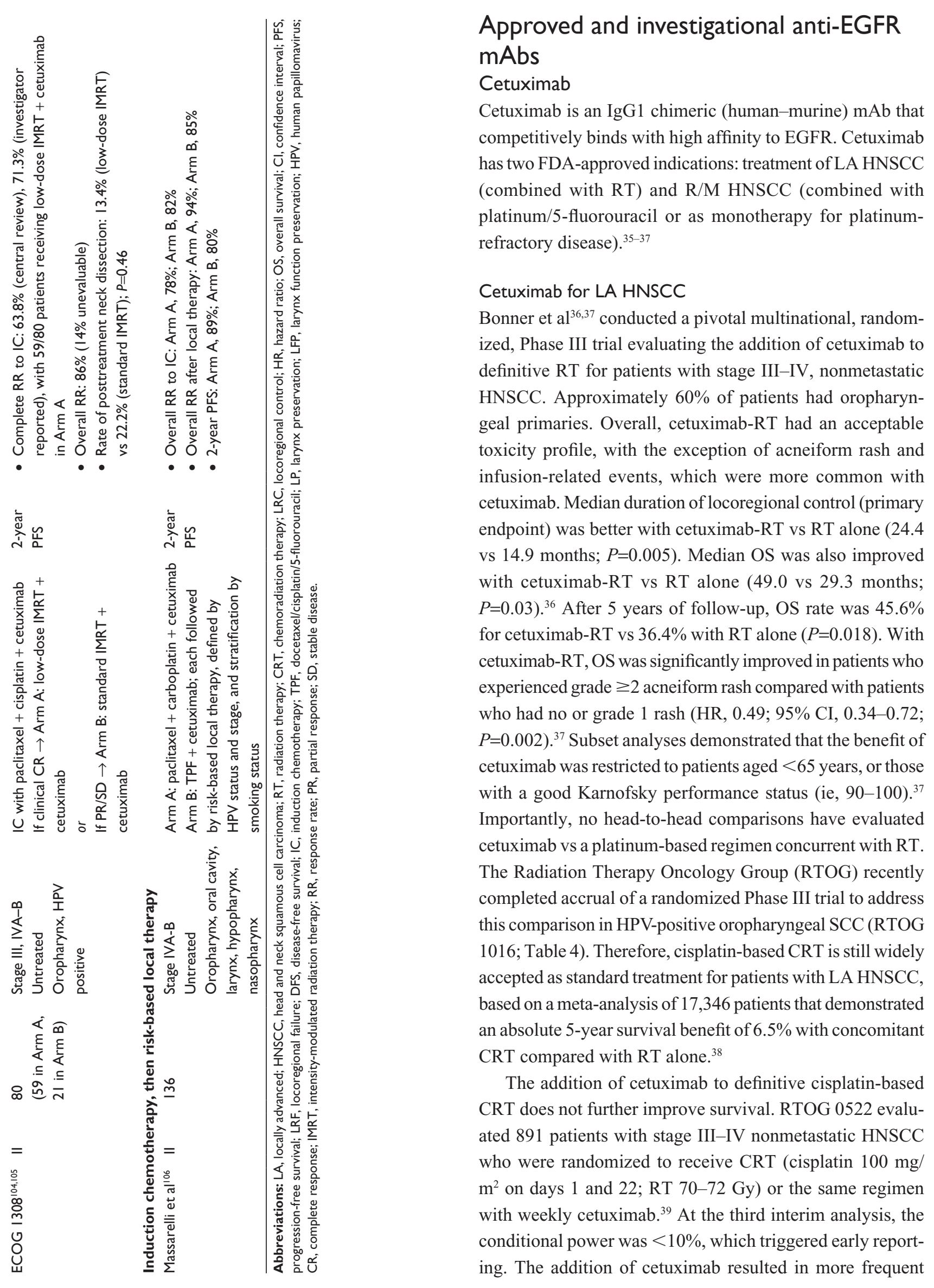




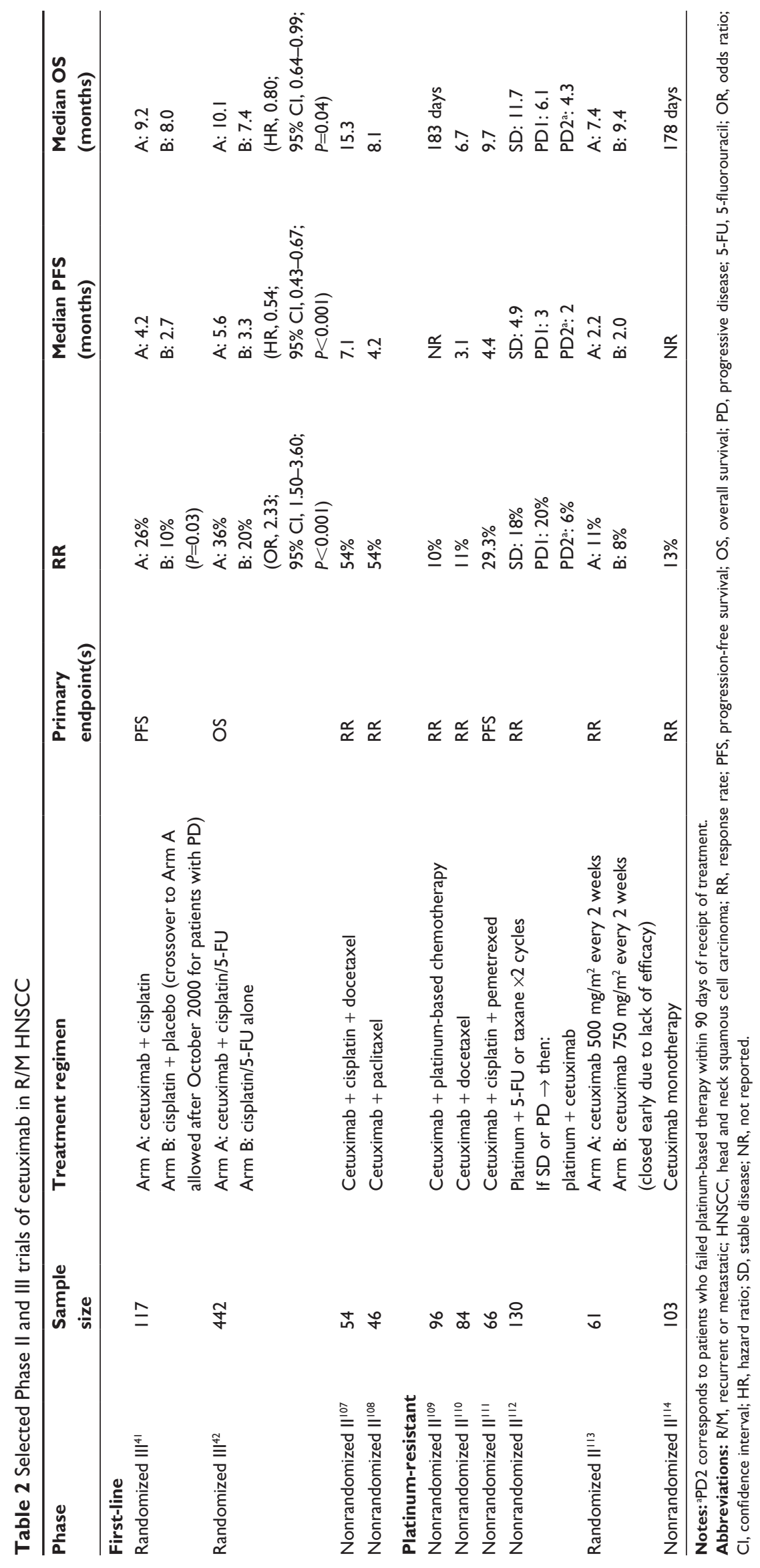




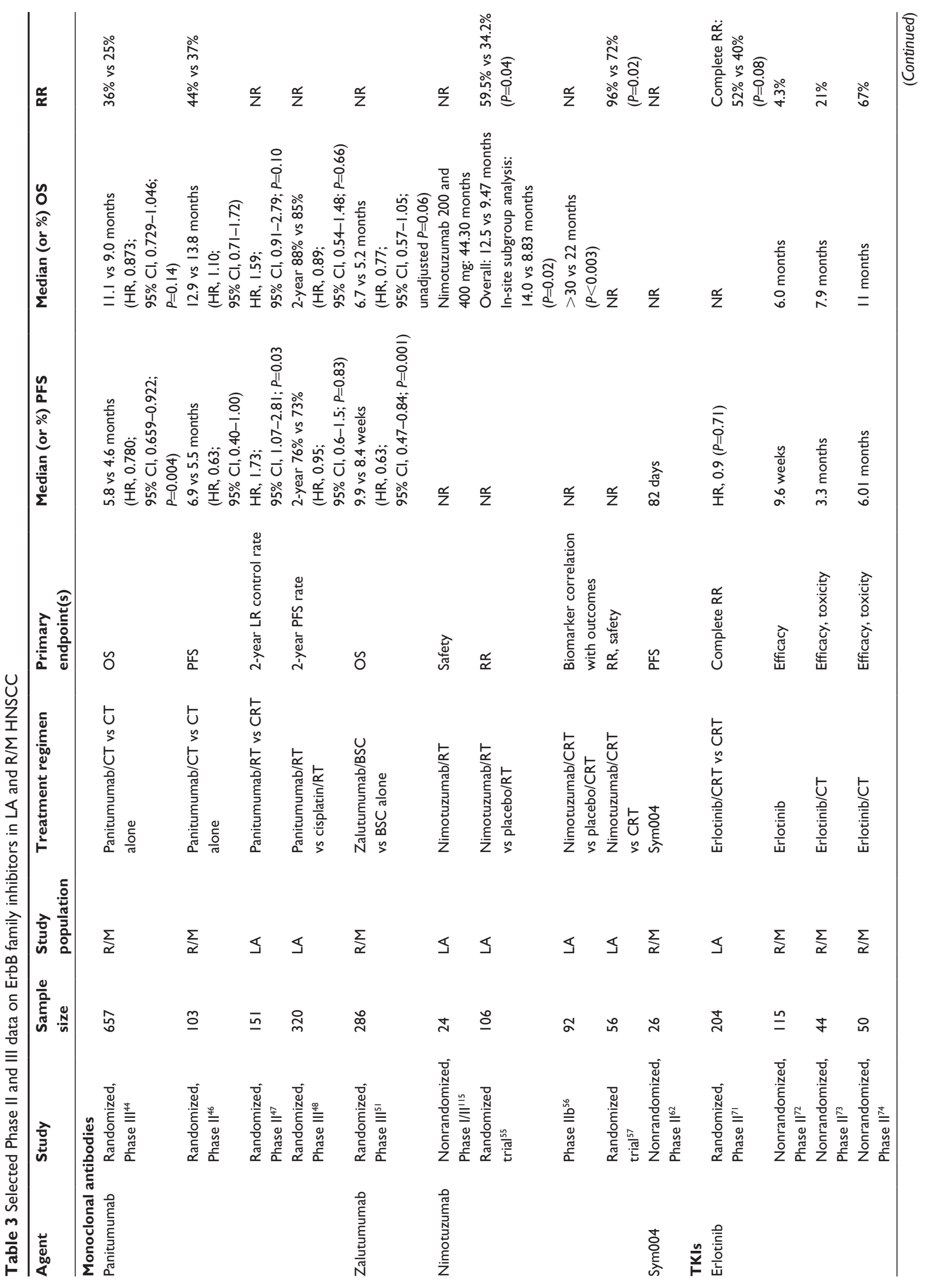




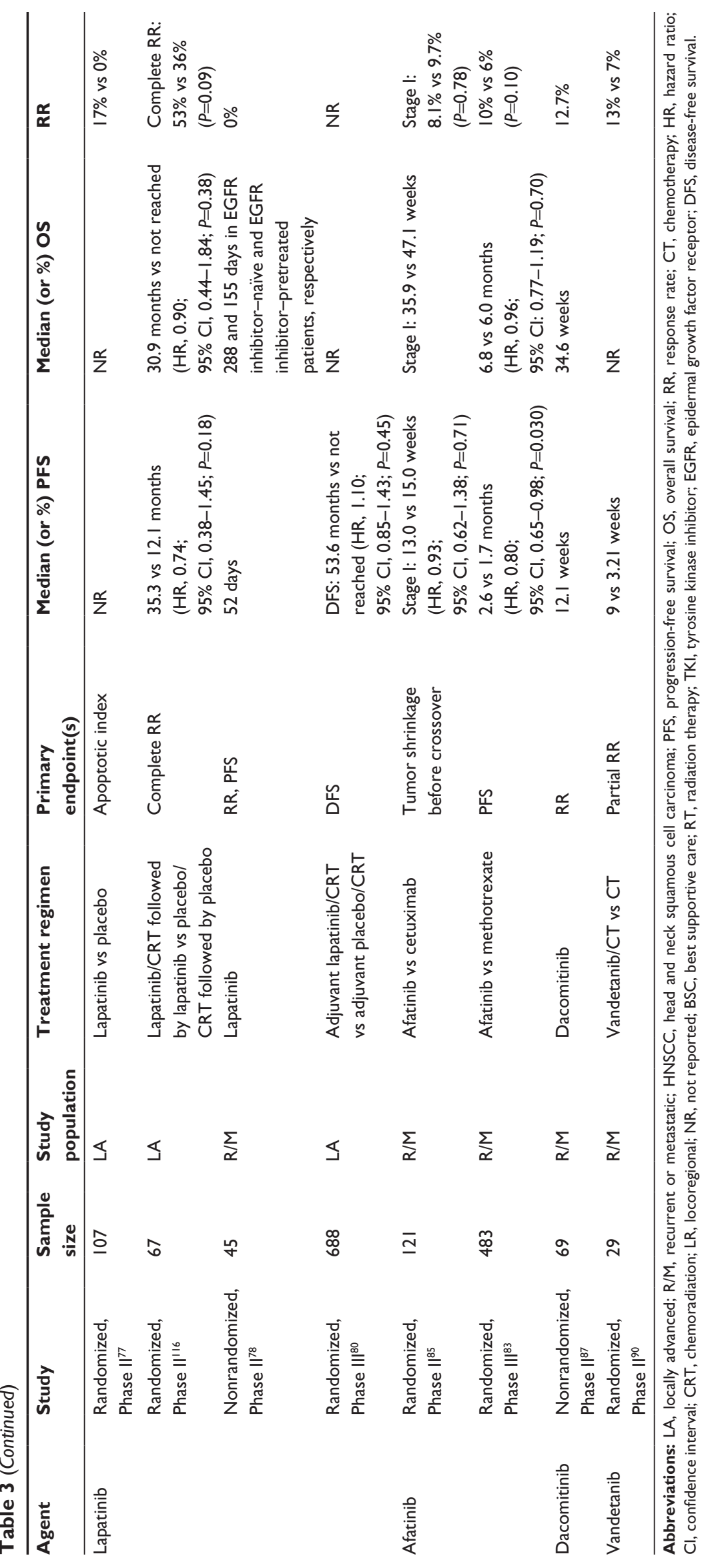




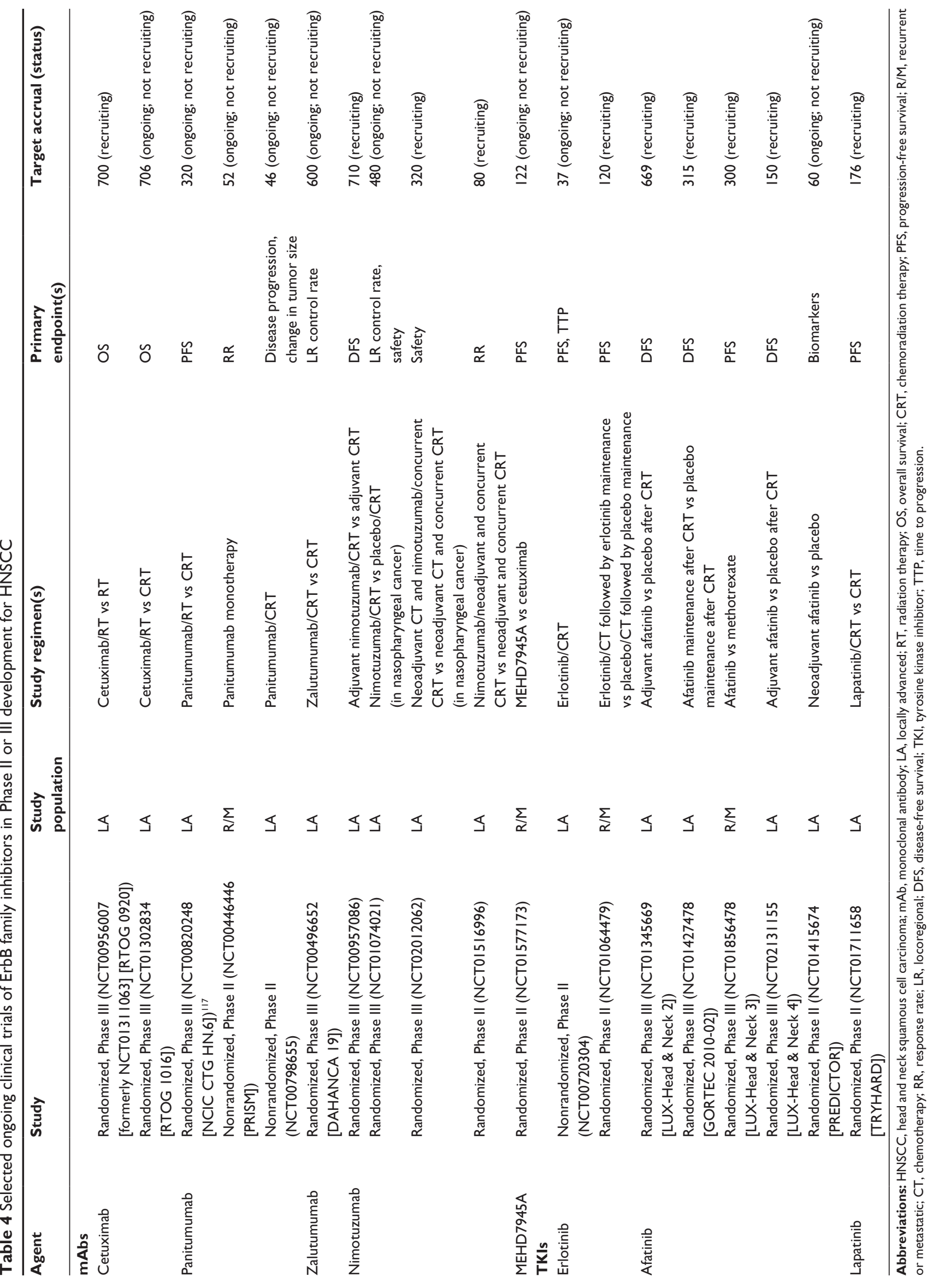


RT interruptions (26.9\% vs $15.1 \%$ for CRT alone); mean cisplatin delivery was similar. Patients with p16-positive OPC had better 3-year probability of progression-free survival (PFS; $72.8 \%$ vs $49.2 \% ; P<0.001)$ and OS (85.6\% vs $60.1 \% ; P<0.001)$ than patients with p16-negative OPC; EGFR expression did not distinguish outcome. Cetuximab had significantly higher rates of acute grade $\geq 3$ mucositis, skin reactions, fatigue, anorexia, and hypokalemia; after 90 days, adverse event (AE) rates were similar.

Integration of cetuximab into a larynx preservation paradigm was evaluated in TREMPLIN, a randomized Phase II trial of 116 patients with stage III-IV laryngeal or hypopharyngeal SCC suitable for total laryngectomy. ${ }^{40}$ After three cycles of induction chemotherapy (cisplatin/ docetaxel/5-fluorouracil), further treatment was based on response to chemotherapy. Patients with $<50 \%$ response received salvage surgery; patients with $\geq 50 \%$ response were randomized to definitive RT (70 Gy) with either highdose cisplatin or concurrent cetuximab $\left(400 \mathrm{mg} / \mathrm{m}^{2}\right.$ loading dose, then $250 \mathrm{mg} / \mathrm{m}^{2}$ weekly). Treatment compliance was higher with cetuximab (71\% completed all weekly doses) vs cisplatin ( $42 \%$ received all three doses). There was no difference in acute grade $\geq 3$ mucositis ( $43 \%$ in each arm), but grade $\geq 3$ in-field dermatitis was more common with cetuximab (57\% vs 26\%). In an intent-to-treat analysis, there was no difference in larynx preservation at 3 months (primary endpoint; 95\% with cisplatin vs 93\% with cetuximab), larynx function preservation ( $87 \%$ vs $82 \%$ ), and OS at 18 months (92\% vs 89\%). Locoregional failure rate (median follow-up, 36 months) was $13.3 \%$ with cisplatin and $21.4 \%$ with cetuximab. However, due to the increased locoregional failure rate with cetuximab, more salvage laryngectomies were performed in the cetuximab arm, ultimately resulting in similar locoregional failure rates ( $13.3 \%$ vs $10.7 \%)$. There was no difference in 2-year laryngoesophageal dysfunctionfree survival rate, a composite endpoint included after the study was designed (79\% vs $72 \%){ }^{40}$

Additional studies of cetuximab integrated into standard platinum-based CRT or with RT alone in the induction or adjuvant settings are summarized in Table 1; ongoing trials with RT are listed in Table 4.

\section{Cetuximab for R/M HNSCC}

The proof-of-principle trial of cetuximab as first-line treatment for R/M HNSCC was published in 2005. ${ }^{41}$ This Eastern Cooperative Oncology Group randomized, multi-institutional, placebo-controlled, Phase III trial of 117 evaluable patients evaluated cisplatin $\left(100 \mathrm{mg} / \mathrm{m}^{2}\right.$ every
4 weeks) with cetuximab (400 $\mathrm{mg} / \mathrm{m}^{2}$ loading dose, then $250 \mathrm{mg} / \mathrm{m}^{2}$ weekly) or placebo. Significant improvement in RR was observed with cetuximab ( $26 \%$ vs $10 \% ; P=0.03)$. While cetuximab had better median PFS (4.2 vs 2.7 months) and OS (9.2 vs 8.0 months), these findings were not statistically significant. The trial, however, was not adequately powered for survival.

Based on these findings, the EXTREME trial confirmed the benefit of adding cetuximab to chemotherapy as firstline treatment for R/M HNSCC. ${ }^{42}$ Four hundred forty-two patients were randomized to cisplatin $\left(100 \mathrm{mg} / \mathrm{m}^{2}\right)$ or carboplatin $(5 \mathrm{mg} / \mathrm{mL} / \mathrm{min})$ on day 1 , followed by 5 -fluorouracil $1,000 \mathrm{mg} / \mathrm{m}^{2}$ daily for 4 days, every 3 weeks for a maximum of six cycles, or the same chemotherapy plus cetuximab (400 mg/m² loading dose, then $250 \mathrm{mg} / \mathrm{m}^{2}$ weekly). Patients in the cetuximab arm with response or stable disease received maintenance cetuximab until disease progression or unacceptable toxicity. Crossover was not allowed. Median OS was 7.4 months with chemotherapy alone vs 10.1 months with cetuximab $(P=0.04)$. Addition of cetuximab also prolonged median PFS (from 3.3 to 5.6 months; $P<0.001$ ) and RR (from $20 \%$ to $36 \% ; P<0.001$ ). These clinical benefits were not associated with adverse quality of life. Of 219 patients receiving cetuximab, $9 \%$ had grade 3 skin reactions and $3 \%$ had grade $\geq 3$ infusion reactions; there were no cetuximabrelated deaths. A subset analysis suggested greater benefit for patients aged $<65$ years and those who had better performance status or received cisplatin. Additional trials have evaluated cetuximab in the first-line setting and for platinumrefractory $\mathrm{R} / \mathrm{M}$ HNSCC (Table 2).

\section{Panitumumab}

Panitumumab is a fully human IgG2 mAb with high affinity for EGFR. ${ }^{43}$ Unlike cetuximab, panitumumab's human structure results in minimal infusion-related reactions. Results of the SPECTRUM trial were recently published. ${ }^{44}$ This was a randomized, multinational, Phase III trial of 657 patients with R/M HNSCC who received cisplatin $\left(100 \mathrm{mg} / \mathrm{m}^{2}\right.$ on day 1$)$ and 5 -fluorouracil $\left(1,000 \mathrm{mg} / \mathrm{m}^{2}\right.$ daily on days $\left.1-4\right)$ every 3 weeks with or without panitumumab $(9 \mathrm{mg} / \mathrm{kg}$ on day 1) until disease progression or for a maximum of six cycles. Patients without disease progression could continue receiving panitumumab maintenance after the initial six cycles of chemotherapy. Crossover was not allowed. There was no significant difference in median OS (primary endpoint; 11.1 vs 9.0 months; $P=0.14$ ). Panitumumab did prolong median PFS by 1.2 months (5.8 vs 4.6 months; $P=0.004$ ). Several grade $\geq 3$ toxicities were more frequent 
with panitumumab, including skin or eye toxicity, diarrhea, hypomagnesemia, and cardiac arrhythmias. There were also more treatment-related deaths with panitumumab (14 [4\%] patients) vs chemotherapy (8 [2\%] patients). A predefined subanalysis evaluating the prognostic implication of HPV status was performed; however, direct comparisons with other trials may be confounded by the low p16 cutoff threshold $(10 \%)$ that was utilized. Furthermore, approximately half of p16-positive tumors involved nonoropharyngeal primaries, for which the relative importance of HPV status remains to be defined. ${ }^{45}$ The randomized Phase II PARTNER trial preliminarily demonstrated improved PFS and RR with docetaxel/cisplatin plus panitumumab vs docetaxel/cisplatin alone as first-line treatment for R/M HNSCC, but with an increased frequency of grade $3 / 4$ AEs (73\% vs 56\%). ${ }^{46}$ For LA HNSCC, the randomized Phase II CONCERT-2 trial of 151 patients receiving panitumumab/RT vs CRT demonstrated trends favoring CRT for 2-year locoregional control (primary endpoint; $51 \%$ with panitumumab/RT vs $61 \%$ with CRT), PFS ( $P=0.03)$, and OS $(P=0.10)$; rates of grade $\geq 3$ AEs were similar ( $85 \%$ vs $81 \%) .{ }^{47}$ More recently, results from the National Cancer Institute of Canada Clinical Trials Group HN.6 Phase III trial of panitumumab/RT (accelerated fractionation) vs cisplatin/RT (standard fractionation) in LA HNSCC were presented, which failed to establish noninferiority for the primary endpoint of 2-year PFS (76\% vs 73\%; $\mathrm{HR}, 0.95 ; 95 \% \mathrm{CI}, 0.6-1.5 ; P=0.83)$ and showed a similar grade $>3$ nonhematologic AE rate $(91 \%$ vs $88 \% ; P=0.25) .{ }^{48}$ In a separately presented quality of life analysis, significant differences favoring the panitumumab arm were seen during the last week of RT; however, there was no durable quality of life benefit relative to cisplatin/RT. ${ }^{49}$ A Phase II study of panitumumab/chemotherapy vs chemotherapy alone in $\mathrm{R} / \mathrm{M}$ HNSCC (NCT00756444) was recently completed and data are forthcoming. Several trials of panitumumab for R/M and LA HNSCC are ongoing (Table 4).

\section{Zalutumumab}

Zalutumumab is a fully human $\mathrm{IgG} 1 \mathrm{mAb}$ that targets EGFR domain III and inhibits binding of EGF and TGF- $\alpha$ to EGFR. ${ }^{50}$ Zalutumumab also prevents conformational changes in EGFR that are necessary for its activation. ${ }^{50}$ An open-label, randomized, Phase III trial investigated zalutumumab plus best supportive care (BSC) vs BSC alone in 286 patients with R/M HNSCC after failure of platinum-based chemotherapy. ${ }^{51}$ Zalutumumab prolonged median PFS compared with BSC alone ( 9.9 vs 8.4 weeks; $P=0.0012$ ). However, the trial failed to meet its primary endpoint of improved median OS (6.7 vs
5.2 months; $P=0.06$ ). The most frequent grade $\geq 3$ AEs with zalutumumab were rash, anemia, and pneumonia. ${ }^{51}$ Although Genmab (Princeton, NJ, USA) suspended clinical development of zalutumumab in $2011,{ }^{50}$ there is an ongoing Phase III trial evaluating zalutumumab combined with definitive CRT for pharyngeal and laryngeal primaries (NCT00496652 [DAHANCA 19]). Preliminary results reported no increase in locoregional control, disease-specific survival, or OS with the addition of zalutumumab to CRT..$^{52}$

\section{Nimotuzumab}

Nimotuzumab is a fully humanized IgG1 mAb that binds domain III of EGFR. ${ }^{53}$ Unlike zalutumumab, nimotuzumab prevents ligand binding, but not conformational receptor changes. ${ }^{54}$ A Phase II, randomized, placebo-controlled, double-blinded trial compared nimotuzumab-RT with placebo-RT in 106 patients with LA HNSCC who were medically unfit for standard CRT. ${ }^{55}$ The primary endpoint of complete RR was met $59.5 \%$ for nimotuzumab-RT vs $34.2 \%$ for RT; $P=0.04$ ). The intent-to-treat analysis demonstrated a nonsignificant trend toward improved median OS with nimotuzumab-RT (12.5 vs 9.47 months). However, in a research site-specific subanalysis of 88 patients, nimotuzumab-RT was associated with significant OS benefit (median 14.0 vs 8.83 months; $P=0.02$ ). Finally, an analysis of median OS by EGFR status showed that it was significantly longer for patients with EGFR-positive tumors who were receiving nimotuzumab vs placebo (16.5 vs 7.2 months; $P=0.004)$. There was no survival advantage for patients with EGFR-negative tumors. No grade $\geq 3$ AEs or skin toxicity were observed. ${ }^{55}$ Another study linking nimotuzumab-elicited outcomes with EGFR expression was a randomized, multicenter, Phase IIb study that divided 92 patients with LA HNSCC into two treatment groups (CRT vs RT for those with poor performance status), further stratified by whether they received nimotuzumab or placebo. ${ }^{56}$ Patients receiving nimotuzumab-CRT had a significantly higher median OS than those receiving placebo-CRT ( $>30$ months vs 22 months; $P<0.003$ ). There was a significant correlation between EGFR expression and improved OS in the nimotuzumab-CRT arm $(P=0.02)$, which remained significant at 24 months $(P=0.01) .{ }^{56}$ Recently, preliminary results of a Phase II trial of 56 patients with LA HNSCC who were randomized to CRT with or without nimotuzumab demonstrated significantly higher RR with nimotuzumab vs CRT alone ( $96 \%$ vs $72 \% ; P=0.02) .{ }^{57}$ Furthermore, there was no potentiation of treatment-related toxicity, suggesting nimotuzumab could be safely added to standard CRT. 
A Phase II study of nimotuzumab/chemotherapy vs chemotherapy alone in LA HNSCC (NCT01425736) was recently completed and data are forthcoming. Several ongoing Phase II and III trials evaluating nimotuzumab for treatment of LA HNSCC are summarized in Table 4.

\section{MEHD7945A and Sym004}

MEHD7945A, a first-in-class human IgG1 mAb targeting EGFR and ErbB3/HER3, ${ }^{58-60}$ will be evaluated vs cetuximab in a Phase II trial in R/M HNSCC (NCT01577173). Sym004, a novel anti-EGFR therapy containing $2 \mathrm{mAbs}$ targeting nonoverlapping epitopes in domain III, ${ }^{61}$ was evaluated in a Phase II study of 26 heavily pretreated patients with R/M HNSCC who developed resistance to anti-EGFR mAb-based therapy. ${ }^{62}$ Preliminary findings revealed tumor shrinkage in 8 patients, while 14 had stable disease; median PFS was 82 days. Skin rash was reported by $96 \%$ of patients, including $42 \%$ with grade $\geq 3$.

\section{Investigational ErbB family TKIs}

While several oral, small-molecule, ErbB family TKIs are being evaluated, none have been approved for HNSCC at the time of publication.

\section{Gefitinib}

Gefitinib is a reversible EGFR TKI. ${ }^{63}$ Based on results from Phase III trials demonstrating that gefitinib has limited activity compared with chemotherapy for R/M HNSCC, ${ }^{64,65}$ there are no known plans for further development of gefitinib in HNSCC.

\section{Erlotinib}

Erlotinib is another reversible EGFR TKI ${ }^{66,67}$ In LA HNSCC, erlotinib has demonstrated modest activity as neoadjuvant monotherapy ${ }^{68}$ combined with definitive CRT, ${ }^{69}$ and with definitive bevacizumab-CRT. ${ }^{70}$ Another Phase II trial, however, demonstrated no improvement in complete RR or PFS when adding erlotinib to definitive CRT for LA HNSCC. ${ }^{71}$

For R/M HNSCC, Phase II data with erlotinib suggest antitumor activity with acceptable tolerability. Erlotinib monotherapy in 115 patients with R/M HNSCC, regardless of HER1/EGFR status, demonstrated an RR of $4.3 \%$ (all partial responses). ${ }^{72}$ There were no differences in PFS or OS in subgroup analyses; however, patients with grade $\geq 2$ rash had significantly higher OS $(P=0.045)$. Skin rash and diarrhea were the most frequently reported drug-related toxicities. A Phase I/II trial of 45 patients receiving cisplatin and erlotinib for R/M HNSCC demonstrated an RR of $21 \%$, median PFS of 3.3 months, and median OS of 7.9 months. ${ }^{73}$ There was minimal grade $\geq 3$ toxicity. A Phase II study of
50 patients receiving erlotinib in combination with cisplatin/ docetaxel for R/M HNSCC demonstrated an RR of $67 \%$ and disease control rate (DCR) of $95 \% .{ }^{74}$ Median OS and PFS at 19 months of follow-up were 11 and 6 months, respectively. Ongoing Phase II trials evaluating erlotinib with CRT for LA HNSCC and with chemotherapy followed by maintenance in R/M HNSCC are summarized in Table 4.

\section{Lapatinib}

Lapatinib is a reversible EGFR and ErbB2/HER2 TKI. ${ }^{75,76}$ A randomized, placebo-controlled, Phase II trial of lapatinib monotherapy followed by definitive CRT demonstrated clinical activity (RR, $17 \%$ vs $0 \%$ with placebo) in 107 patients with treatment-naïve LA HNSCC. ${ }^{77}$ In the R/M HNSCC setting, however, a Phase II trial of 45 patients receiving lapatinib monotherapy demonstrated good tolerability but no responses. ${ }^{78}$ Evaluation of lapatinib in Phase II trials with induction chemotherapy was discouraged after Phase I results demonstrated unacceptable toxicities (predominantly renal failure) when combined with standard induction regimens for LA laryngeal and hypopharyngeal SCC. ${ }^{79}$ A recently completed placebo-controlled Phase III trial of adjuvant lapatinib plus CRT followed by 1 year of lapatinib maintenance in patients with resected, high-risk HNSCC did not improve DFS. ${ }^{80}$ Ongoing Phase II trials are evaluating lapatinib with definitive CRT followed by 1 year of lapatinib maintenance for LA HNSCC (NCT00387127) and definitive RT for LA HNSCC in patients who cannot tolerate concurrent CRT (NCT00490061).

\section{Afatinib}

Afatinib is an irreversible ErbB family inhibitor (targets include EGFR, ErbB2/HER2, and ErbB4/HER4) ${ }^{81,82}$ Five Phase III studies are evaluating afatinib for LA HNSCC as adjuvant therapy and for R/M HNSCC as monotherapy or in combination with chemotherapy (Tables 3 and 4). In the LUX-Head \& Neck 1 trial of afatinib vs methotrexate in R/M HNSCC after failure of platinum-based therapy, afatinib was associated with a significant improvement in the primary endpoint of PFS compared with methotrexate (2.6 vs 1.7 months; $P=0.030$ ); OS was not improved $(P=0.70) .{ }^{83}$ The objective RR was $10 \%$ with afatinib (vs $6 \%$ with methotrexate), and DCR was $49 \%$ (vs 39\%). PFS benefit was associated with positive patient-reported outcomes, with afatinib-treated patients reporting less pain, improved swallowing, and delayed deterioration of global health status. In subgroup analyses, patients with p16-negative non-OPC and local recurrence (rather than metastasis) without prior EGFRtargeted $\mathrm{mAb}$ therapy seemed to derive the most benefit from afatinib. The most common grade 3/4 treatment-related AEs 
were rash/acne (10\%) and diarrhea (9\%). A more recently presented biomarker analysis found a propensity for greater PFS benefit with afatinib vs methotrexate in the settings of p16-negative (2.7 vs 1.6 months; HR, 0.70; $P=0.029$ ), PTENhigh (2.9 vs 1.4 months; HR, 0.36; $P=0.014$ ), HER3-low ( 2.9 vs 2.0 months; HR, $0.47 ; P=0.014$ ), and $E G F R$-amplified (2.8 vs 2.2 months; HR, $0.64 ; P=0.162$ ) disease.$^{84}$ Final results of a randomized, open-label, Phase II study that compared afatinib to cetuximab in 124 patients with platinum-refractory R/M HNSCC were recently published. ${ }^{85}$ In stage I, patients were randomized to daily afatinib or weekly cetuximab until disease progression or unacceptable toxicity, at which time crossover was permitted (stage II). Stage I results demonstrated comparable antitumor activity (tumor shrinkage, RR) and median PFS (13.0 weeks with afatinib vs 15.0 weeks with cetuximab; $P=0.71)$. Approximately half $(56 \%)$ the patients crossed over to the other treatment arm (stage II); disease progression was the primary reason. DCR by independent central review was $33 \%$ for afatinib (vs 19\% with cetuximab), and median PFS was 9.3 weeks (vs 5.7 weeks) during stage II. Grade $\geq 3$ toxicities were more frequent in patients treated with afatinib (47\% vs 16\%). The authors concluded that patients may benefit from sequential therapy, especially treatment with afatinib after cetuximab failure. ${ }^{85}$ Other Phase II trials of afatinib include one in a neoadjuvant setting (NCT01538381 [EORTC NOCI-HNCG]), another to evaluate potential biomarkers (NCT01415674 [PREDICTOR]), and another in HPV-negative LA HNSCC as a component of induction chemotherapy (NCT01732640).

\section{Dacomitinib}

Dacomitinib is an irreversible TKI that targets EGFR, ErbB2/HER2, and ErbB4/HER4. ${ }^{86}$ A Phase II study of dacomitinib monotherapy in 69 patients with R/M HNSCC demonstrated an RR of $12.7 \%$; median PFS and OS were 12.1 and 34.6 weeks, respectively. ${ }^{87}$ Diarrhea, acneiform dermatitis, and fatigue were the most frequent grade $\geq 3$ AEs. An ongoing placebo-controlled, Phase I/II study seeks to identify biomarker modulations associated with dacomitinib treatment when given preoperatively for resectable oral cavity HNSCC (NCT01116843).

\section{Vandetanib}

Vandetanib is a multitargeted TKI, including EGFR and vascular endothelial growth factor receptor $2{ }^{88,89}$ Preliminary results of vandetanib plus docetaxel $(n=15)$ vs docetaxel alone $(\mathrm{n}=14)$ for $\mathrm{R} / \mathrm{M}$ HNSCC demonstrated a partial $\mathrm{RR}$ of $13 \%$ with vandetanib plus docetaxel vs $7 \%$ with docetaxel alone, and a median PFS of 9 vs 3.2 weeks; serious AEs were comparable between arms. ${ }^{90}$ A Phase II trial of vandetanib with adjuvant CRT in high-risk, stage III-IV HNSCC was terminated early due to withdrawal of study drug; as only 34 of 170 planned patients were accrued, no analysis was performed (NCT00720083).

\section{Perspectives}

EGFR overexpression and its key role in HNSCC carcinogenesis make EGFR inhibition a promising molecular treatment strategy. Two classes of ErbB inhibitors are available: mAbs and small-molecule TKIs. To date, cetuximab remains the only FDA-approved ErbB family inhibitor for HNSCC. For LA disease, cetuximab is approved in combination with definitive RT; however, studies are ongoing to provide direct comparisons with platinum-based regimens. In $\mathrm{R} / \mathrm{M}$ disease, cetuximab is approved both in combination with platinum-containing regimens and as monotherapy for platinum-refractory disease. The limited effect of other EGFR inhibitors in HNSCC could be explained by the different mechanisms of action of mAbs and TKIs. Notably, cetuximab has been shown to elicit an antibody-dependent cellular cytotoxicity response that is dependent on EGFR expression levels in HNSCC. ${ }^{91,92}$ Overexpression of EGFR and other ErbB family receptors, ErbB ligands, and downstream pathway components in HNSCC may promote positive feedback of the pathway. ${ }^{93}$ In cell lines, kinase-inactive EGFR can dimerize with ErbB2 and activate signaling downstream of EGFR, suggesting that the presence of EGFR is important for promoting cell survival, even in the absence of EGFR kinase activity. ${ }^{94}$ Kinase-inactive EGFR has also been shown to physically interact with several cancer-related proteins, including Axl and ephrin type-A receptor $2 .{ }^{95}$ Furthermore, EGFR has been shown to have kinase-independent roles in maintaining intracellular glucose levels and initiating autophagy, both of which contribute to increased cell survival. ${ }^{96,97}$ This evidence for functions of EGFR beyond its tyrosine kinase role may partially explain the lack of substantial efficacy of EGFR TKIs in EGFR-overexpressing cancers like HNSCC.

Because EGFR mutations are rarely detected in $\mathrm{HNSCC},{ }^{93}$ there is also a need to identify biomarkers to predict those patients most likely to benefit from EGFR-targeted agents, and lack of patient selection may partially explain the minimal responses observed thus far with the majority of EGFR inhibitors tested in HNSCC. Rash has been suggested to be a biomarker for EGFR inhibitor response and has been associated with improved outcomes in several tumor types, including HNSCC. ${ }^{98}$ In two HNSCC trials, statistically significant improvements in OS have been observed in patients who developed grade $\geq 2$ skin rash following either 
erlotinib or cetuximab treatment compared with patients who developed no or grade 1 skin rash. ${ }^{37,72}$ Similarly, in a trial evaluating gefitinib in patients with R/M HNSCC, grade of skin toxicity positively correlated with DCR, PFS, and OS. ${ }^{99}$ Although the mechanism by which EGFR inhibitors cause dermatological toxicity is not fully understood, there is evidence to suggest that immune cell infiltration and inhibition of EGFR homodimer signaling may be associated with these skin toxicities. ${ }^{100,101}$

\section{Conclusion}

Although ErbB family members represent valid therapeutic targets in HNSCC, the modest RR seen with ErbB family inhibitors illustrates the need for continued research to identify potential resistance mechanisms and biomarkers for response. A detailed understanding of the role this family plays in the pathogenesis of HNSCC is critical so that we may further exploit this promising treatment strategy in our effort to maximize patient survival.

\section{Acknowledgments}

The authors received no direct compensation related to the development of the manuscript. Writing, editorial support, and formatting assistance were provided by Melissa Brunckhorst, PhD, of MedErgy, which was contracted and funded by Boehringer Ingelheim Pharmaceuticals, Inc. (BIPI). BIPI was given the opportunity to review the manuscript for medical and scientific accuracy as well as intellectual property considerations.

\section{Author contributions}

All authors made substantial contributions to conception and design, acquisition of data, or analysis and interpretation of data; took part in either drafting the article or revising it critically for important intellectual content; gave final approval of the version to be published; and agree to be accountable for all aspects of the work.

\section{Disclosure}

The authors report no conflicts of interest in this work.

\section{References}

1. Ferlay J, Soerjomataram I, Dikshit R, et al. Cancer incidence and mortality worldwide: sources, methods and major patterns in GLOBOCAN 2012. Int J Cancer. 2015;136(5):E359-E386.

2. American Cancer Society. Cancer Facts \& Figures, 2014. Atlanta, GA: American Cancer Society; 2014.

3. Argiris A, Karamouzis MV, Raben D, Ferris RL. Head and neck cancer. Lancet. 2008;371(9625):1695-1709.

4. Blot WJ, McLaughlin JK, Winn DM, et al. Smoking and drinking in relation to oral and pharyngeal cancer. Cancer Res. 1988;48(11): 3282-3287.
5. Gillison ML, Chaturvedi AK, Lowy DR. HPV prophylactic vaccines and the potential prevention of noncervical cancers in both men and women. Cancer. 2008;113(10 Suppl):3036-3046.

6. Sturgis EM, Cinciripini PM. Trends in head and neck cancer incidence in relation to smoking prevalence: an emerging epidemic of human papillomavirus-associated cancers? Cancer. 2007;110(7):1429-1435.

7. Klein G. The relationship of the virus to nasopharyngeal carcinoma. In: Epstein M, Achong B, editors. The Epstein-Barr Virus. Berlin, Germany: Springer-Verlag; 1979:339-350.

8. Seiwert TY, Cohen EE. State-of-the-art management of locally advanced head and neck cancer. Br J Cancer. 2005;92(8):1341-1348.

9. National Comprehensive Cancer Network. NCCN Clinical Practice Guidelines in Oncology ${ }^{\mathrm{TM}}$. Head and Neck Cancers. Version 2.2014. Available from: http://www.nccn.org/professionals/physician_gls/PDF/ head-and-neck.pdf. Accessed September 22, 2014.

10. Gibson MK, Li Y, Murphy B, et al. Randomized phase III evaluation of cisplatin plus fluorouracil versus cisplatin plus paclitaxel in advanced head and neck cancer (E1395): an intergroup trial of the Eastern Cooperative Oncology Group. J Clin Oncol. 2005;23(15):3562-3567.

11. Colevas AD. Chemotherapy options for patients with metastatic or recurrent squamous cell carcinoma of the head and neck. J Clin Oncol. 2006;24(17):2644-2652.

12. Dassonville O, Formento JL, Francoual M, et al. Expression of epidermal growth factor receptor and survival in upper aerodigestive tract cancer. J Clin Oncol. 1993;11(10):1873-1878.

13. Rubin Grandis J, Melhem MF, Barnes EL, Tweardy DJ. Quantitative immunohistochemical analysis of transforming growth factor-alpha and epidermal growth factor receptor in patients with squamous cell carcinoma of the head and neck. Cancer. 1996;78(6):1284-1292.

14. Santini J, Formento JL, Francoual M, et al. Characterization, quantification, and potential clinical value of the epidermal growth factor receptor in head and neck squamous cell carcinomas. Head Neck. 1991;13(2): 132-139.

15. Rubin Grandis J, Melhem MF, Gooding WE, et al. Levels of TGFalpha and EGFR protein in head and neck squamous cell carcinoma and patient survival. J Natl Cancer Inst. 1998;90(11):824-832.

16. Ang KK, Berkey BA, Tu X, et al. Impact of epidermal growth factor receptor expression on survival and pattern of relapse in patients with advanced head and neck carcinoma. Cancer Res. 2002;62(24):7350-7356.

17. Xia W, Lau YK, Zhang HZ, et al. Combination of EGFR, HER-2/neu, and HER-3 is a stronger predictor for the outcome of oral squamous cell carcinoma than any individual family members. Clin Cancer Res. 1999;5(12):4164-4174.

18. O-charoenrat P, Rhys-Evans PH, Archer DJ, Eccles SA. C-erbB receptors in squamous cell carcinomas of the head and neck: clinical significance and correlation with matrix metalloproteinases and vascular endothelial growth factors. Oral Oncol. 2002;38(1):73-80.

19. Bazley LA, Gullick WJ. The epidermal growth factor receptor family. Endocr Relat Cancer. 2005;12(Suppl 1):S17-S27.

20. Hynes NE, Lane HA. ERBB receptors and cancer: the complexity of targeted inhibitors. Nat Rev Cancer. 2005;5(5):341-354.

21. Egloff AM, Grandis JR. Targeting epidermal growth factor receptor and SRC pathways in head and neck cancer. Semin Oncol. 2008;35(3): 286-297.

22. Baselga J, Arteaga CL. Critical update and emerging trends in epidermal growth factor receptor targeting in cancer. J Clin Oncol. 2005;23(11): 2445-2459.

23. Ganly I, Talbot S, Carlson D, et al. Identification of angiogenesis/ metastases genes predicting chemoradiotherapy response in patients with laryngopharyngeal carcinoma. J Clin Oncol. 2007;25(11): 1369-1376.

24. Takikita M, Xie R, Chung JY, et al. Membranous expression of Her3 is associated with a decreased survival in head and neck squamous cell carcinoma. J Transl Med. 2011;9:126.

25. Barker FG, Simmons ML, Chang SM, et al. EGFR overexpression and radiation response in glioblastoma multiforme. Int J Radiat Oncol Biol Phys. 2001;51(2):410-418. 
26. Erjala K, Sundvall M, Junttila TT, et al. Signaling via ErbB2 and ErbB3 associates with resistance and epidermal growth factor receptor (EGFR) amplification with sensitivity to EGFR inhibitor gefitinib in head and neck squamous cell carcinoma cells. Clin Cancer Res. 2006;12(13):4103-4111.

27. Schmidt-Ullrich RK, Mikkelsen RB, Dent P, et al. Radiation-induced proliferation of the human A431 squamous carcinoma cells is dependent on EGFR tyrosine phosphorylation. Oncogene. 1997;15(10):1191-1197.

28. Bowers G, Reardon D, Hewitt T, et al. The relative role of ErbB1-4 receptor tyrosine kinases in radiation signal transduction responses of human carcinoma cells. Oncogene. 2001;20(11):1388-1397.

29. Contessa JN, Hampton J, Lammering G, et al. Ionizing radiation activates Erb-B receptor dependent Akt and p70 S6 kinase signaling in carcinoma cells. Oncogene. 2002;21(25):4032-4041.

30. Dittmann K, Mayer C, Fehrenbacher B, et al. Radiation-induced epidermal growth factor receptor nuclear import is linked to activation of DNAdependent protein kinase. J Biol Chem. 2005;280(35):31182-31189.

31. Dittmann K, Mayer C, Kehlbach R, Rodemann HP. Radiation-induced caveolin-1 associated EGFR internalization is linked with nuclear EGFR transport and activation of DNA-PK. Mol Cancer. 2008;7:69.

32. Kavanagh BD, Lin PS, Chen P, Schmidt-Ullrich RK. Radiation-induced enhanced proliferation of human squamous cancer cells in vitro: a release from inhibition by epidermal growth factor. Clin Cancer Res. 1995;1(12) 1557-1562.

33. Abhold EL, Kiang A, Rahimy E, et al. EGFR kinase promotes acquisition of stem cell-like properties: a potential therapeutic target in head and neck squamous cell carcinoma stem cells. PLoS One. 2012;7(2):e32459.

34. Bozec A, Peyrade F, Fischel JL, Milano G. Emerging molecular targeted therapies in the treatment of head and neck cancer. Expert Opin Emerg Drugs. 2009;14(2):299-310.

35. ERBITUX ${ }^{\circledR}$ (cetuximab) injection, for intravenous infusion [package insert]. Branchburg, NJ: ImClone LLC; 2013.

36. Bonner JA, Harari PM, Giralt J, et al. Radiotherapy plus cetuximab for squamous-cell carcinoma of the head and neck. $N$ Engl J Med. 2006 354(6):567-578.

37. Bonner JA, Harari PM, Giralt J, et al. Radiotherapy plus cetuximab for locoregionally advanced head and neck cancer: 5-year survival data from a phase 3 randomised trial, and relation between cetuximabinduced rash and survival. Lancet Oncol. 2010;11(1):21-28.

38. Pignon JP, le Maître A, Maillard E, Bourhis J. Meta-analysis of chemotherapy in head and neck cancer (MACH-NC): an update on 93 randomised trials and 17,346 patients. Radiother Oncol. 2009;92(1):4-14.

39. Ang KK, Zhang Q, Rosenthal DI, et al. Randomized phase III trial of concurrent accelerated radiation plus cisplatin with or without cetuximab for stage III to IV head and neck carcinoma: RTOG 0522. J Clin Oncol. 2014;32(27):2940-2950.

40. Lefebvre JL, Pointreau Y, Rolland F, et al. Induction chemotherapy followed by either chemoradiotherapy or bioradiotherapy for larynx preservation: the TREMPLIN randomized phase II study. J Clin Oncol. 2013;31(7):853-859.

41. Burtness B, Goldwasser MA, Flood W, Mattar B, Forastiere AA. Phase III randomized trial of cisplatin plus placebo compared with cisplatin plus cetuximab in metastatic/recurrent head and neck cancer: an Eastern Cooperative Oncology Group study. J Clin Oncol. 2005;23(34): 8646-8654.

42. Vermorken JB, Mesia R, Rivera F, et al. Platinum-based chemotherapy plus cetuximab in head and neck cancer. $N$ Engl J Med. 2008;359(11): $1116-1127$.

43. Yang XD, Jia XC, Corvalan JR, Wang P, Davis CG. Development of ABX-EGF, a fully human anti-EGF receptor monoclonal antibody, for cancer therapy. Crit Rev Oncol Hematol. 2001;38(1):17-23.

44. Vermorken JB, Stohlmacher-Williams J, Davidenko I, et al. Cisplatin and fluorouracil with or without panitumumab in patients with recurrent or metastatic squamous-cell carcinoma of the head and neck (SPECTRUM): an open-label phase 3 randomised trial. Lancet Oncol. 2013; 14(8):697-710.
45. Chung C, Isaranuwatchai W, Di Maio M, et al. Economic analysis of TORCH: erlotinib versus cisplatin and gemcitabine as first-line therapy for advanced non-small cell lung cancer (NSCLC). J Clin Oncol. 2013; 31(Suppl):Abstract e19031.

46. Wirth LJ, Dakhil SR, Kornek G, et al. PARTNER: a randomized phase II study of docetaxel/cisplatin (doc/cis) chemotherapy with or without panitumumab (pmab) as first-line treatment (tx) for recurrent or metastatic squamous cell carcinoma of the head and neck (R/M SCCHN). J Clin Oncol. 2013;31(Suppl):Abstract 6029.

47. Giralt J, Trigo JM, Nuyts S, et al. Phase 2, randomized trial (CONCERT-2) of panitumumab (PMAB) plus radiotherapy (PRT) compared with chemoradiotherapy (CRT) in patients (PTS) with unresected, locally advanced squamous cell carcinoma of the head and neck (LASCCHN) [Abstract 1016O]. Ann Oncol. 2012;23(Suppl 9):ix334.

48. Siu LL, Waldron JN, Chen BE, et al. Phase III randomized trial of standard fractionation radiotherapy (SFX) with concurrent cisplatin (CIS) versus accelerated fractionation radiotherapy (AFX) with panitumumab (PMab) in patients (pts) with locoregionally advanced squamous cell carcinoma of the head and neck (LA-SCCHN): NCIC Clinical Trials Group HN.6 trial. J Clin Oncol. 2015;33(Suppl):Abstract 6000.

49. Ringash J, Waldron JN, Siu LL, et al. Quality of life (QOL) in a phase III randomized trial of standard fractionation radiotherapy (SFX) with concurrent cisplatin (CIS) versus accelerated fractionation radiotherapy (AFX) with panitumumab (PMab) in patients (pts) with locoregionally advanced squamous cell carcinoma of the head and neck (LA-SCCHN): NCIC Clinical Trials Group HN.6 (NCT00820248). J Clin Oncol. 2015;33(Suppl):Abstract 6053.

50. Schick U, Gujral DM, Richards TM, Harrington KJ, Nutting CM. Zalutumumab in head and neck cancer. Expert Opin Biol Ther. 2012; 12(1):119-125.

51. Machiels JP, Subramanian S, Ruzsa A, et al. Zalutumumab plus best supportive care versus best supportive care alone in patients with recurrent or metastatic squamous-cell carcinoma of the head and neck after failure of platinum-based chemotherapy: an open-label, randomised phase 3 trial. Lancet Oncol. 2011;12(4):333-343.

52. Eriksen JG, Maare C, Johansen J, et al. DAHANCA 19: first results of a randomized phase III study of the importance of the EGFR-inhibitor zalutumumab for the outcome of primary curative radiotherapy for squamous cell carcinoma of the head and neck. Late breaking abstract presented at: The European Cancer Congress, September 27-October 1, 2013, Amsterdam, Netherlands. Abstract 12.

53. Boland WK, Bebb G. Nimotuzumab: a novel anti-EGFR monoclonal antibody that retains anti-EGFR activity while minimizing skin toxicity. Expert Opin Biol Ther. 2009;9(9):1199-1206.

54. Talavera A, Friemann R, Gomez-Puerta S, et al. Nimotuzumab, an antitumor antibody that targets the epidermal growth factor receptor, blocks ligand binding while permitting the active receptor conformation. Cancer Res. 2009;69(14):5851-5859.

55. Rodriguez MO, Rivero TC, del Castillo BR, et al. Nimotuzumab plus radiotherapy for unresectable squamous-cell carcinoma of the head and neck. Cancer Biol Ther. 2010;9(5):343-349.

56. Basavaraj C, Sierra P, Shivu J, Melarkode R, Montero E, Nair P. Nimotuzumab with chemoradiation confers a survival advantage in treatment-naive head and neck tumors over expressing EGFR. Cancer Biol Ther. 2010;10(7):673-681.

57. Bhatnagar AR, Singh DP, Sharma R, et al. A comparative study of monoclonal antibody against EGFR (nimotuzumab) used in combination with chemoradiation versus chemoradiation alone in the treatment of locally advanced inoperable squamous cell carcinoma of the head and neck. J Clin Oncol. 2012;30(Suppl):Abstract e16012.

58. Kamath AV, Lu D, Gupta P, et al. Preclinical pharmacokinetics of MEHD7945A, a novel EGFR/HER3 dual-action antibody, and prediction of its human pharmacokinetics and efficacious clinical dose. Cancer Chemother Pharmacol. 2012;69(4):1063-1069.

59. Schaefer G, Haber L, Crocker LM, et al. A two-in-one antibody against HER3 and EGFR has superior inhibitory activity compared with monospecific antibodies. Cancer Cell. 2011;20(4):472-486. 
60. Huang S, Li C, Armstrong EA, et al. Dual targeting of EGFR and HER3 with MEHD7945A overcomes acquired resistance to EGFR inhibitors and radiation. Cancer Res. 2013;73(2):824-833.

61. Pedersen MW, Jacobsen HJ, Koefoed K, et al. Sym004: a novel synergistic anti-epidermal growth factor receptor antibody mixture with superior anticancer efficacy. Cancer Res. 2010;70(2):588-597.

62. Machiels J-PH, Specenier PM, Krauss J, et al. Sym004, a novel strategy to target EGFR with an antibody mixture, in patients with advanced SCCHN progressing after anti-EGFR monoclonal antibody: a proof of concept study. J Clin Oncol. 2013;31(Suppl):Abstract 6002.

63. Adamo V, Franchina T, Adamo B, et al. Gefitinib in lung cancer therapy: Clinical results, predictive markers of response and future perspectives. Cancer Biol Ther. 2009;8(3):206-212.

64. Stewart JS, Cohen EE, Licitra L, et al. Phase III study of gefitinib compared with intravenous methotrexate for recurrent squamous cell carcinoma of the head and neck. J Clin Oncol. 2009;27(11):1864-1871.

65. Argiris A, Ghebremichael M, Gilbert J, et al. Phase III randomized, placebo-controlled trial of docetaxel with or without gefitinib in recurrent or metastatic head and neck cancer: an Eastern Cooperative Oncology Group trial. J Clin Oncol. 2013;31(11):1405-1414.

66. Cohen MH, Johnson JR, Chen YF, Sridhara R, Pazdur R. FDA drug approval summary: erlotinib (Tarceva) tablets. Oncologist. 2005;10(7): 461-466.

67. Tarceva ${ }^{\circledR}$ (erlotinib tablets) [package insert]. South San Francisco, CA: Genentech, Inc.; 2013.

68. Thomas F, Rochaix P, Benlyazid A, et al. Pilot study of neoadjuvant treatment with erlotinib in nonmetastatic head and neck squamous cell carcinoma. Clin Cancer Res. 2007;13(23):7086-7092.

69. Herchenhorn D, Dias FL, Viegas CM, et al. Phase I/II study of erlotinib combined with cisplatin and radiotherapy in patients with locally advanced squamous cell carcinoma of the head and neck. Int J Radiat Oncol Biol Phys. 2010;78(3):696-702.

70. Hainsworth JD, Spigel DR, Greco FA, et al. Combined modality treatment with chemotherapy, radiation therapy, bevacizumab, and erlotinib in patients with locally advanced squamous carcinoma of the head and neck: a phase II trial of the Sarah Cannon oncology research consortium. Cancer J. 2011;17(5):267-272.

71. Martins RG, Parvathaneni U, Bauman JE, et al. Cisplatin and radiotherapy with or without erlotinib in locally advanced squamous cell carcinoma of the head and neck: a randomized phase II trial. $J$ Clin Oncol. 2013;31(11):1415-1421.

72. Soulieres D, Senzer NN, Vokes EE, Hidalgo M, Agarwala SS, Siu LL. Multicenter phase II study of erlotinib, an oral epidermal growth factor receptor tyrosine kinase inhibitor, in patients with recurrent or metastatic squamous cell cancer of the head and neck. J Clin Oncol. 2004; 22(1):77-85.

73. Siu LL, Soulieres D, Chen EX, et al. Phase I/II trial of erlotinib and cisplatin in patients with recurrent or metastatic squamous cell carcinoma of the head and neck: a Princess Margaret Hospital phase II consortium and National Cancer Institute of Canada Clinical Trials Group Study. J Clin Oncol. 2007;25(16):2178-2183.

74. Kim ES, Kies MS, Glisson BS, et al. Final results of a phase II study of erlotinib, docetaxel and cisplatin in patients with recurrent/metastatic head and neck cancer. J Clin Oncol. 2007;25(18S):Abstract 6013.

75. Kondo N, Tsukuda M, Ishiguro Y, et al. Antitumor effects of lapatinib (GW572016), a dual inhibitor of EGFR and HER-2, in combination with cisplatin or paclitaxel on head and neck squamous cell carcinoma. Oncol Rep. 2010;23(4):957-963.

76. TYKERB ${ }^{\circledR}$ (lapatinib) tablets [package insert]. Research Triangle Park, NC: GlaxoSmithKline; 2012.

77. Del Campo JM, Hitt R, Sebastian P, et al. Effects of lapatinib monotherapy: results of a randomised phase II study in therapy-naive patients with locally advanced squamous cell carcinoma of the head and neck. Br J Cancer. 2011;105(5):618-627.

78. de Souza JA, Davis DW, Zhang Y, et al. A phase II study of lapatinib in recurrent/metastatic squamous cell carcinoma of the head and neck. Clin Cancer Res. 2012;18(8):2336-2343.
79. Lalami Y, Specenier PM, Awada A, et al. EORTC 24051: unexpected side effects in a phase I study of TPF induction chemotherapy followed by chemoradiation with lapatinib, a dual EGFR/ErbB2 inhibitor, in patients with locally advanced resectable larynx and hypopharynx squamous cell carcinoma. Radiother Oncol. 2012;105(2):238-240.

80. Harrington KJ, Temam S, D'Cruz A, et al. Final analysis: a randomized, blinded, placebo (P)-controlled phase III study of adjuvant postoperative lapatinib (L) with concurrent chemotherapy and radiation therapy (CH-RT) in high-risk patients with squamous cell carcinoma of the head and neck (SCCHN). J Clin Oncol. 2014;32(5s): Abstract 6005.

81. Li D, Ambrogio L, Shimamura T, et al. BIBW2992, an irreversible EGFR/HER2 inhibitor highly effective in preclinical lung cancer models. Oncogene. 2008;27(34):4702-4711.

82. Solca F, Dahl G, Zoephel A, et al. Target binding properties and cellular activity of afatinib (BIBW 2992), an irreversible ErbB family blocker. J Pharmacol Exp Ther. 2012;343(2):342-350.

83. Machiels JP, Haddad RI, Fayette J, et al. Afatinib versus methotrexate as second-line treatment in patients with recurrent or metastatic squamous-cell carcinoma of the head and neck progressing on or after platinum-based therapy (LUX-Head \& Neck 1): an open-label, randomised phase 3 trial. Lancet Oncol. 2015;16(5):583-594.

84. Cohen EEW, Fayette LJ, Gauler TC, et al. Biomarker analysis in recurrent and/or metastatic head and neck squamous cell carcinoma (R/M HNSCC) patients (pts) treated with second-line afatinib versus methotrexate (MTX): LUX-Head \& Neck 1 (LUX-H\&N1). J Clin Oncol. 2015;33(Suppl):Abstract 6023.

85. Seiwert TY, Fayette J, Cupissol D, et al. A randomized, phase II study of afatinib versus cetuximab in metastatic or recurrent squamous cell carcinoma of the head and neck. Ann Oncol. 2014;25(9):1813-1820.

86. Gonzales AJ, Hook KE, Althaus IW, et al. Antitumor activity and pharmacokinetic properties of PF-00299804, a second-generation irreversible pan-erbB receptor tyrosine kinase inhibitor. Mol Cancer Ther. 2008;7(7):1880-1889.

87. Abdul Razak AR, Soulieres D, Laurie SA, et al. A phase II trial of dacomitinib, an oral pan-human EGF receptor (HER) inhibitor, as firstline treatment in recurrent and/or metastatic squamous-cell carcinoma of the head and neck. Ann Oncol. 2013;24(3):761-769.

88. Wedge SR, Ogilvie DJ, Dukes M, et al. ZD6474 inhibits vascular endothelial growth factor signaling, angiogenesis, and tumor growth following oral administration. Cancer Res. 2002;62(16):4645-4655.

89. CAPRELSA ${ }^{\circledR}$ (vandetanib) tablets [prescribing information]. Wilmington, DE: AstraZeneca Pharmaceuticals LP; 2011.

90. Limaye S, Riley S, Zhao S, et al. A randomized phase II study of docetaxel with or without vandetanib in recurrent or metastatic squamous cell carcinoma of head and neck (SCCHN). Oral Oncol. 2013;49(8): 835-841.

91. Hansen AR, Siu LL. Epidermal growth factor receptor targeting in head and neck cancer: have we been just skimming the surface? J Clin Oncol. 2013;31(11):1381-1383.

92. Kimura H, Sakai K, Arao T, Shimoyama T, Tamura T, Nishio K. Antibody-dependent cellular cytotoxicity of cetuximab against tumor cells with wild-type or mutant epidermal growth factor receptor. Cancer Sci. 2007;98(8):1275-1280.

93. Kalyankrishna S, Grandis JR. Epidermal growth factor receptor biology in head and neck cancer. J Clin Oncol. 2006;24(17):2666-2672.

94. Deb TB, Su L, Wong L, et al. Epidermal growth factor (EGF) receptor kinase-independent signaling by EGF. J Biol Chem. 2001;276(18): 15554-15560.

95. Gusenbauer S, Vlaicu P, Ullrich A. HGF induces novel EGFR functions involved in resistance formation to tyrosine kinase inhibitors. Oncogene. 2013;32(33):3846-3856.

96. Weihua Z, Tsan R, Huang WC, et al. Survival of cancer cells is maintained by EGFR independent of its kinase activity. Cancer Cell. 2008;13(5):385-393.

97. Tan X, Thapa N, Sun Y, Anderson RA. A kinase-independent role for EGF receptor in autophagy initiation. Cell. 2015;160(1-2):145-160. 
98. Dienstmann R, Brana I, Rodon J, Tabernero J. Toxicity as a biomarker of efficacy of molecular targeted therapies: focus on EGFR and VEGF inhibiting anticancer drugs. Oncologist. 2011;16(12):1729-1740.

99. Cohen EE, Kane MA, List MA, et al. Phase II trial of gefitinib $250 \mathrm{mg}$ daily in patients with recurrent and/or metastatic squamous cell carcinoma of the head and neck. Clin Cancer Res. 2005;11(23):8418-8424.

100. Solomon BM, Jatoi A. Rash from EGFR inhibitors: opportunities and challenges for palliation. Curr Oncol Rep. 2008;10(4):304-308.

101. Laux I, Jain A, Singh S, Agus DB. Epidermal growth factor receptor dimerization status determines skin toxicity to HER-kinase targeted therapies. Br J Cancer. 2006;94(1):85-92.

102. Salama JK, Haddad RI, Kies MS, et al. Clinical practice guidance for radiotherapy planning after induction chemotherapy in locoregionally advanced head-and-neck cancer. Int J Radiat Oncol Biol Phys. 2009;75(3):725-733.

103. Mesia R, Rueda A, Vera R, et al. Adjuvant therapy with cetuximab for locally advanced squamous cell carcinoma of the oropharynx: results from a randomized, phase II prospective trial. Ann Oncol. 2013;24(2): 448-453.

104. Marur S, Lee J-W, Cmelak A, et al. ECOG 1308: a phase II trial of induction chemotherapy followed by cetuximab with low dose versus standard dose IMRT in patients with HPV-associated resectable squamous cell carcinoma of the oropharynx (OP). J Clin Oncol. 2012;30(Suppl):Abstract 5566.

105. Marur S, Li S, Cmelak A, et al. E 1308: a phase II trial of induction chemotherapy (IC) followed by cetuximab with low dose versus standard dose IMRT in patients with human papilloma virus (HPV)associated resectable squamous cell carcinoma of the oropharynx (OPSCC). J Clin Oncol. 2013;31(Supp1):Abstract 6005.

106. Massarelli E, Haddad RI, Lee JJ, et al. Weekly paclitaxel, carboplatin, cetuximab (PCC), and cetuximab, docetaxel, cisplatin, and fluorouracil (C-TPF), followed by risk-based local therapy in previously untreated, locally advanced head and neck squamous cell carcinoma (LAHNSCC). J Clin Oncol. 2015;33(Suppl):Abstract 6001.

107. Guigay J, Fayette J, Dillies AF, et al. Cetuximab, docetaxel, and cisplatin (TPEx) as first-line treatment in patients with recurrent or metastatic (R/M) squamous cell carcinoma of the head and neck (SCCHN): final results of phase II trial GORTEC 2008-03. J Clin Oncol. 2012;30(Suppl):Abstract 5505.

108. Hitt R, Irigoyen A, Cortes-Funes H, Grau JJ, Garcia-Saenz JA, CruzHernandez JJ. Phase II study of the combination of cetuximab and weekly paclitaxel in the first-line treatment of patients with recurrent and/or metastatic squamous cell carcinoma of head and neck. Ann Oncol. 2012;23(4):1016-1022.
109. Baselga J, Trigo JM, Bourhis J, et al. Phase II multicenter study of the antiepidermal growth factor receptor monoclonal antibody cetuximab in combination with platinum-based chemotherapy in patients with platinum-refractory metastatic and/or recurrent squamous cell carcinoma of the head and neck. J Clin Oncol. 2005;23(24):5568-5577.

110. Knoedler M, Dietz A, Gauler TC, et al. Cetuximab, fluorouracil (5-FU), cisplatin, and docetaxel as first-line treatment in patients with recurrent and/or metastatic squamous cell carcinoma of the head and neck (R/M SCCHN): interim results of a randomized phase II clinical trial (CeFCiD). J Clin Oncol. 2013;31(Suppl):Abstract e17021.

111. Vermorken JB, Licitra L, Stohlmacher-Williams J, et al. Phase II study of pemetrexed in combination with cisplatin and cetuximab in recurrent or metastatic squamous cell carcinoma of the head and neck. Eur J Cancer. 2013;49(13):2877-2883.

112. Herbst RS, Arquette M, Shin DM, et al. Phase II multicenter study of the epidermal growth factor receptor antibody cetuximab and cisplatin for recurrent and refractory squamous cell carcinoma of the head and neck. J Clin Oncol. 2005;23(24):5578-5587.

113. Fury MG, Sherman E, Lisa D, et al. A randomized phase II study of cetuximab every 2 weeks at either 500 or $750 \mathrm{mg} / \mathrm{m}^{2}$ for patients with recurrent or metastatic head and neck squamous cell cancer. $J$ Natl Compr Canc Netw. 2012;10(11):1391-1398.

114. Vermorken JB, Trigo J, Hitt R, et al. Open-label, uncontrolled, multicenter phase II study to evaluate the efficacy and toxicity of cetuximab as a single agent in patients with recurrent and/or metastatic squamous cell carcinoma of the head and neck who failed to respond to platinumbased therapy. J Clin Oncol. 2007;25(16):2171-2177.

115. Crombet T, Osorio M, Cruz T, et al. Use of the humanized anti-epidermal growth factor receptor monoclonal antibody h-R3 in combination with radiotherapy in the treatment of locally advanced head and neck cancer patients. J Clin Oncol. 2004;22(9):1646-1654.

116. Harrington K, Berrier A, Robinson M, et al. Randomised phase II study of oral lapatinib combined with chemoradiotherapy in patients with advanced squamous cell carcinoma of the head and neck: rationale for future randomised trials in human papilloma virus-negative disease. Eur J Cancer. 2013;49(7):1609-1618.

117. Waldron JN, Parulekar W, O'Sullivan B, et al. A phase III study of standard fractionation radiotherapy with concurrent high-dose cisplatin versus accelerated fractionation radiotherapy (RT) with panitumumab in patients with locally advanced stage III and IV squamous cell carcinoma of the head and neck (SCCHN) (NCIC Clinical Trials Group HN.6). J Clin Oncol. 2012;30(Suppl):Abstract TPS5600.
OncoTargets and Therapy

\section{Publish your work in this journal}

OncoTargets and Therapy is an international, peer-reviewed, open access journal focusing on the pathological basis of all cancers, potential targets for therapy and treatment protocols employed to improve the management of cancer patients. The journal also focuses on the impact of management programs and new therapeutic agents and protocols on

\section{Dovepress}

patient perspectives such as quality of life, adherence and satisfaction. The manuscript management system is completely online and includes a very quick and fair peer-review system, which is all easy to use. Visit http://www.dovepress.com/testimonials.php to read real quotes from published authors. 